\title{
Diagnostic Value of Non-specific Clinical and Laboratory Findings in Patients Suspected of Crimean-Congo Hemorrhagic Fever in an Endemic Region
}

Aziz Ahmad Hamidi ${ }^{10}$, Serhat Kescioğlu² (D)

1 Infectious Diseases and Clinical Microbiology Department, Maltepe University School of Medicine, İstanbul, Turkey

2 Infectious Diseases and Clinical Microbiology Department, Eskişehir Yunus Emre State Hospital, Eskişehir, Turkey

\begin{abstract}
Background: We aimed to determine diagnostic sensitivity and specificity of clinical and laboratory findings in patients with Crimean-Congo hemorrhagic fever (CCHF).

Methods: We retrospectively reviewed the characteristics of patients who were suspected of CCHF. The patients were stratified into two groups as positive and negative based on results of CCHF specific IgM and viral RNA by real-time polymerase chain reaction (RT-PCR).

Results: Mean age of 125 patients included (55.2\% women, $44.8 \%$ men) was $47 \pm 20$ years. The highest sensitivity (95\%) was in myalgia. When the association of multiple findings were assessed, the highest sensitivity was found for myalgia plus transaminase elevation (Odds ratio [OR] 9.3; 95\% confidence interval [CI] 3.75-23.05; $p<0.05$ ). The highest specificity was found for myalgia plus history of husbandry plus transaminase elevation (OR 15; 95\% CI 5.27-42.68; $p<0.05$.

Conclusion: If patients have myalgia and transaminase elevation with a history of husbandry at endemic regions, CCHF should be considered.

Keywords: Crimean-Congo hemorrhagic fever, thrombocytopenia, hemorrhagic fever, tick exposure, diagnostic value
\end{abstract}

\section{INTRODUCTION}

T The Crimean-Congo hemorrhagic fever (CCHF) is caused by a RNA virus (Nairovirus) Bunyaviridae family. It is generally transmitted by tick bite (Hyalomma marginatum), particularly in spring and summer, and the blood of viremic animals (1). The CCHF has the most widespread geographic distribution among tick-borne infections and it is endemic approximately in 30 countries in Africa, Asia, Southeastern Europe and the Middle East. In Turkey, CCHF was first described in 2002, and the crude fatality rate was calculated as $5 \%(2-4)$. Originally, it was seen in the northern provinc-
Corresponding Author: Aziz Ahmad Hamidi

E-mail:

azizahmadhamidi@gmail.com

Received: September 12, 2021 Accepted: October 22, 2021 Published: December 30, 2021

\section{Suggested citation:}

Hamidi AA, Kescioğlu S. Diagnostic value of non-specific clinical and laboratory findings in patients suspected of CrimeanCongo hemorrhagic fever in an endemic region. Infect Dis Clin Microbiol 2021; 3: 145-151.

DOI: $10.36519 /$ idem.2021.91 
es of Central Anatolia and the eastern provinces of the Karadeniz region. However, recent reports show that it has become increasingly common with cases from different regions $(1,5,6)$.

The mean incubation period is 2-7 days and may prolong up to 12 days. In symptomatic cases, non-specific symptoms such as fever, myalgia and headache are seen during the pre-hemorrhagic phase while epistaxis, hematemesis and melena are the most common symptoms during the hemorrhagic phase. Thrombocytopenia is almost universal and transient leucopenia may also be detected. In addition, elevated transaminase levels can also be observed due to hepatic injury $(2,7,8)$. Detection of specific IgM and IgG antibodies using immunofluorescence assay (IFA) and viral RNA using real-time polymerase chain reaction (RT-PCR) are used in the diagnosis (9). In previous studies, the rate of tick bite history ranged from $60 \%$ to $73 \%$ in cases with CCHF $(2,4,10)$. Thus, CCHF is suspected in cases presented with non-specific findings regardless of tick bite history in endemic regions. This results in the overuse of specific diagnostic tools and delays in the diagnosis of cases with CCHF. There is a limited number of studies on diagnostic sensitivity and specificity of clinical findings and routine laboratory tests before using specific diagnostic tools.

We aimed to estimate diagnostic sensitivity and specificity of clinical and laboratory findings in patients with suspected CCHF.

\section{METHODS}

The study was approved by the Ethics Committee on Non-Interventional Clinical Trials of Karabük University. The study included patients (aged $>18$ years) who admitted to the infectious disease department with an initial diagnosis of CCHF. Data regarding age, gender, history of husbandry or agriculture, tick bite history, presenting complaints (fever, myalgia, headache, hemorrhage, nausea and vomiting) and laboratory findings at presentation including leukocyte and platelet count, hemoglobin, transaminases, LDH, creatinine and INR were retrospectively extracted from hospital database and patients' files for all cases. The patients with platelet count $<150,000 /$ $\mathrm{mm}^{3}$ were considered as thrombocytopenia. Pa- tients were assigned into groups according to platelet count: $<20,000,20,000-49,000,50,000-99,000$ and $100,000-149,000 / \mathrm{mm}^{3}$. The patients with aspartate aminotransferase > 250 IU/L and/or alanine aminotransferase $\geq 40 I U / L$ were considered to have transaminase elevation. Lactate dehydrogenase (LDH) elevation was defined as LDH>250 U/L. Creatinine value $<1.4 \mathrm{mg} / \mathrm{dl}$ was considered as normal while creatinine level $\geq 1.5 \mathrm{mg} / \mathrm{dL}$ was defined as high. The international normalized ratio (INR) was also recorded. INR values were classified into two groups: $<1.2$ and 1.2. The patients with specific IgM antibodies as detected by IFA or positive RT-PCR results were defined as CCHF-positive, while those with negative IgM antibodies and RT-PCR were defined as CCHF-negative. Demographic characteristics and laboratory findings were compared between CCHF-positive and CCHF-negative groups.

We analyzed data using SPSS software version 15 for Windows (SPSS Inc, Chicago, IL, USA). Descriptive statistics were presented as mean, standard deviation, median, minimum and maximum. The Chi-square test was used to assess categorical variables while Student's t test was used to assess variables with normal distribution. Mann-Whitney $\mathrm{U}$ test was used to assess variables with skewed distribution. Statistical significance was set as $p<0.05$. For variables with a significant difference, diagnostic sensitivity, specificity, positive predictive value, negative predictive value, odds ratio and $95 \%$ confidence interval were calculated.

\section{HIGHLIGHTS}

- Working in agriculture-husbandry and having myalgia and transaminase elevation are significant for performing specific diagnostic tests in endemic regions.

- The highest sensitivity was found for myalgia plus transaminase elevation.

- The highest specificity was found for myalgia plus history of husbandry plus transaminase elevation.

- All thrombocytopenic patients are not diagnosed with CCHF in the endemic area because just thrombocytopenia has the lowest specificity. 


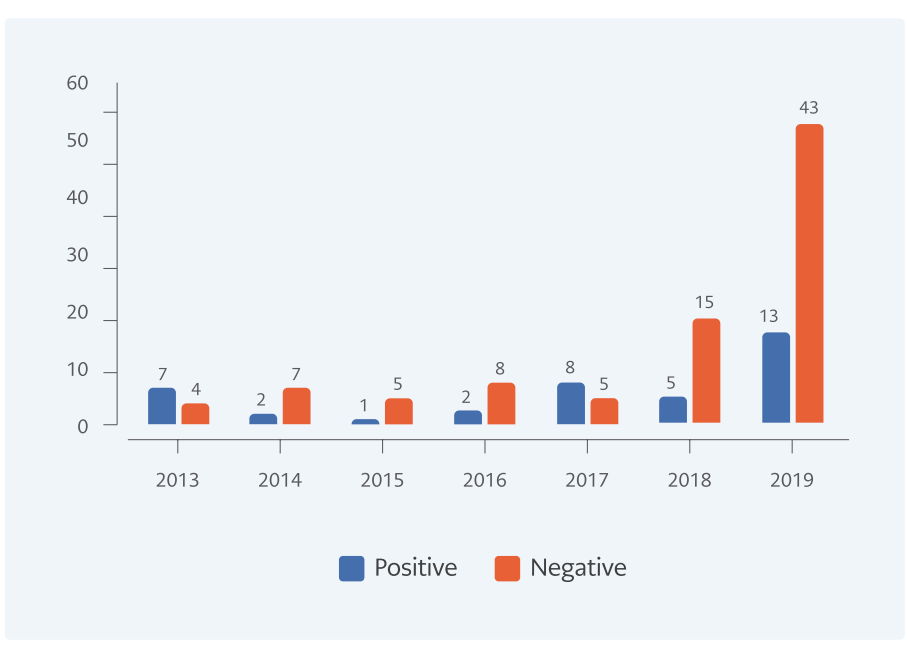

Figure 1. Distribution of Crimean-Congo Hemorrhagic test positivity among the suspected cases by the year.

\section{RESULTS}

Of 125 patients included, 55.2\% were female and $44.8 \%$ were male. The mean age was $47 \pm 20$ years. The most common presenting complaint was myalgia (68.8\%), while the most common laboratory finding was thrombocytopenia (60\%). The history of a tick bite was detected in $41.6 \%$ of cases, and the occupation of $31.2 \%$ was husbandry. Table 1 presents demographic, clinical and laboratory characteristics of cases. CCHF was diagnosed in $30 \%$ ( $n=38$ ) of cases, and specific CCHF tests were found to be negative in $70 \%(\mathrm{n}=87)$. In the CCHF-positive group, a specific IgM antibody was detected in three cases (7.9\%) using the ELISA method, and in the rest of the group, viral RNA was shown using RT-PCR.

Clinical and laboratory characteristics were compared between CCHF positive and negative patients (Table 2). Diagnostic sensitivity, specificity, positive predictive and negative predictive values were calculated for variables found to be significantly different between groups (Table 3). The highest sensitivity and negative predictive value were detected for myalgia (95\% and 95\%, respectively). Normal creatinine value found to be insignificant (OR: 7.10; 95\% CI: 0.88-56.07; $p>0.05$ ). When the association of multiple findings were assessed, the highest sensitivity (79\%) was found for myalgia plus transaminase elevation (OR: 9.3; 95\% CI: $3.75-23.05 ; p<0.05)$. The highest specificity (93\%) was found for myalgia plus history of hus-
Table 1. Clinical and Laboratory characteristics of all the patients who were suspected of Crimean-Congo Hemorrhagic Fever.

\begin{tabular}{|l|c|}
\hline & $\mathrm{n}=125(\%)$ \\
\hline Male & $56(44.8)$ \\
\hline Female & $69(55.2)$ \\
\hline Age (Mean; SD) & $47.02 ; 20$ \\
\hline Husbandry & $39(31.2)$ \\
\hline History of tick bite & $52(41.6)$ \\
\hline Fever & $5(44)$ \\
\hline Bleeding & $4(3.2)$ \\
\hline Headache & $48(38.4)$ \\
\hline Nausea and vomiting & $36(28.8)$ \\
\hline Myalgia & $86(68.8)$ \\
\hline Leukopenia & $41(32.8)$ \\
\hline Anemia & $24(19.2)$ \\
\hline Thrombocytopenia & $75(66)$ \\
\hline $\begin{array}{c}\text { Degree of thrombocytopenia } \\
<20,000 \\
20,000-49,000\end{array}$ & $110000-99,000$ \\
\hline $\begin{array}{l}\text { 100,000-149,000 } \\
\text { INR } 1.2\end{array}$ & $15(12)$ \\
\hline Transaminase elevation & $91(7.2)$ \\
\hline Lactate dehydrogenase elevation & $35(28)$ \\
\hline Creatinine & $20(16)$ \\
\hline
\end{tabular}

bandry plus transaminase elevation (OR: $15 ; 95 \%$ CI: 5.27-42.68; $p<0.05$ ) (Table 4).

When the distribution of cases was assessed according to years, seven (64\%) of 11 patients in 2013 , two $(22 \%)$ of nine in 2014 , one $(17 \%)$ of six in 2015 , two $(20 \%)$ of ten in 2016, eight (62\%) of 13 in 2017 , five (25\%) of 20 in 2018, and 13 (23\%) of 56 in 2019 were CCHF positive (Figure 1). Two patients with positive results died because of massive bleeding and intravascular coagulopathy during follow-up; however, 36 patients achieved complete recovery. One patient with epistaxis at presentation was also 
Table 2. Clinical and laboratory characteristics of CCHF-positive and CCHF-negative cases.

\begin{tabular}{|c|c|c|c|}
\hline Characteristics & $\begin{array}{c}\text { CCHF-positive } \\
n=38(\%)\end{array}$ & $\begin{array}{c}\text { CCHF-negative } \\
n=87(\%)\end{array}$ & $p$ \\
\hline Male & $19(50)$ & $50(57.4)$ & 0.44 \\
\hline Age (Mean; SD) & $47.9 ; 15.6$ & $54.45 ; 21.5$ & 0.52 \\
\hline Husbandry & $23(60.5)$ & $16(18.4)$ & $<0.001$ \\
\hline History of tick bite & $22(57.9)$ & $30(34.5)$ & 0.02 \\
\hline Fever & $23(60.5)$ & $32(36.8)$ & 0.01 \\
\hline Bleeding & $1(2.6)$ & $3(3.4)$ & 0.06 \\
\hline Headache & $21(55.3)$ & $27(31)$ & 0.01 \\
\hline Nausea and vomiting & $13(34.2)$ & $23(26.4)$ & 0.37 \\
\hline Myalgia & $36(94.7)$ & $50(57.5)$ & $<0.001$ \\
\hline Leukopenia & $26(68.4)$ & $15(17.2)$ & $<0.001$ \\
\hline Anemia & $5(13.2)$ & $19(21.8)$ & 0.26 \\
\hline Thrombocytopenia & $31(81.6)$ & $44(50.6)$ & 0.001 \\
\hline $\begin{array}{l}\text { Levels of thrombocytopenia } \\
\qquad \begin{array}{l}<20,000 \\
20,000-49,000 \\
50,000-99,000 \\
100,000-149,000\end{array}\end{array}$ & $\begin{array}{c}3(10) \\
2(6.5) \\
21(67.7) \\
5(16.1)\end{array}$ & $\begin{array}{c}6(13.6) \\
9(20.5) \\
14(31.8) \\
15(34.1)\end{array}$ & $\begin{array}{c}0.60 \\
0.09 \\
<0.001 \\
0.08\end{array}$ \\
\hline $\begin{aligned} \text { INR } & \\
& >1.2 \\
& <1.2\end{aligned}$ & $\begin{array}{c}5(13.2) \\
33(86.8)\end{array}$ & $\begin{array}{l}19(21.8) \\
68(78.2)\end{array}$ & 0.26 \\
\hline Transaminase elevation & $31(81.6)$ & $30(34.5)$ & $<0.001$ \\
\hline Lactate dehydrogenase elevation & $21(55.3)$ & $23(26.4)$ & 0.002 \\
\hline $\begin{array}{c}\text { Creatinine } \\
\quad<1.4 \\
\geq 1.5\end{array}$ & $\begin{array}{c}37(97.4) \\
1(2,6)\end{array}$ & $\begin{array}{l}73(83.9) \\
14(16.1)\end{array}$ & 0.03 \\
\hline Myalgia + thrombocytopenia & $29(76.3)$ & $34(39.1)$ & $<0.001$ \\
\hline Myalgia + transaminase elevation & $30(79)$ & $25(28.7)$ & $<0.001$ \\
\hline Husbandry + thrombocytopenia & $19(50)$ & $12(13.8)$ & $<0.001$ \\
\hline Husbandry + transaminase elevation & $21(55.3)$ & $7(8)$ & $<0.001$ \\
\hline Myalgia + husbandry +thrombocytopenia & $18(47.4)$ & $9(10.3)$ & $<0.001$ \\
\hline Myalgia + husbandry + transaminase elevation & $20(52.6)$ & $6(6.9)$ & $<0.001$ \\
\hline
\end{tabular}

discharged after resolution of epistaxis. Among cases in the negative group, HIV-related thrombocytopenia was detected in one patient while myelodysplastic syndrome in one and immune thrombocytopenic purpura in two patients. Non-specific viral infection was diagnosed in 83 cases in the negative group.

\section{DISCUSSION}

CCHF virus is mostly transmitted mainly by a tick bite, direct contact to blood and secretions of viremic animals and as occupational contamination in healthcare providers. It was shown that, albeit rare, it can be transmitted sexually or with ma- 
Table 3. Diagnostic values of clinical and laboratory characteristics.

\begin{tabular}{|c|c|c|c|c|}
\hline Variable & Sensitivity (\%) & $\begin{array}{c}\text { Specificity } \\
(\%)\end{array}$ & $\begin{array}{l}\text { Positive } \\
\text { predictive } \\
\text { value (\%) }\end{array}$ & $\begin{array}{l}\text { Negative } \\
\text { predictive } \\
\text { value (\%) }\end{array}$ \\
\hline Fever & 60 & 63 & 41 & 79 \\
\hline Headache & 55 & 69 & 44 & 78 \\
\hline Myalgia & 95 & 42 & 42 & 95 \\
\hline History of tick bite & 58 & 66 & 42 & 78 \\
\hline Husbandry & 60 & 82 & 59 & 83 \\
\hline Leucopenia & 68 & 83 & 63 & 86 \\
\hline Thrombocytopenia & 82 & 49 & 41 & 86 \\
\hline Lactate dehydrogenase elevation & 55 & 74 & 48 & 79 \\
\hline Transaminase elevation & 82 & 65 & 51 & 89 \\
\hline Creatinine $(<1.4)$ & 97 & 16 & 34 & 93 \\
\hline Myalgia+thrombocytopenia & 76 & 61 & 46 & 86 \\
\hline Myalgia + transaminase elevation & 79 & 71 & 55 & 89 \\
\hline Husbandry + thrombocytopenia & 50 & 86 & 61 & 80 \\
\hline Husbandry + transaminase elevation & 55 & 92 & 75 & 83 \\
\hline Myalgia + husbandry + thrombocytopenia & 47 & 90 & 67 & 80 \\
\hline Myalgia + husbandry + tranaminase elevation & 53 & 93 & 77 & 82 \\
\hline
\end{tabular}

ternal transmission (11-13). It is more commonly seen in male patients working in agriculture or husbandry (4). In our study, male: female ratio was comparable between the groups, while history of husbandry was found to be more common (60.5\%) in the positive group $(p<0.001)$. The rate of tick bite history varies from $60 \%$ to $73 \%$ in the literature (2, $4,10)$. We found as $57.9 \%$ in the positive group, indicating a lower rate compared to the literature. However, it was significantly higher when compared to the negative group (34.5\%; $p=0.02$ ).

In previous studies, fever, myalgia, headache, nausea and vomiting have been identified as the most prominent clinical symptoms $(7,8,14,15)$. In our study, fever, headache and myalgia rates were significantly higher in the positive group; however, nausea and vomiting rates were comparable between groups. Of the cases included, one presented at hemorrhagic phase with epistaxis while two patients progressed into hemorrhagic phase during follow-up. No significant difference was detected in the finding of hemorrhage between positive and negative groups.

Leukopenia, thrombocytopenia and elevated transaminase, creatinine phosphokinase (CPK) and LDH are common laboratory findings in CCHF. In addition, prolonged prothrombin time (PT) and activated partial thromboplastin time (aPTT) elevated CCHF and increased INR values are generally detected during the hemorrhagic phase (7). In a study by Gozdas et al., rates of leucopenia, thrombocytopenia, transaminase elevation and LDH elevation were higher in the positive group than in the negative group $(93.5 \%, 93.5 \%, 67.7 \%$ and $87.1 \%$, respectively) (16). Similarly, they were found to be higher in the positive group in our study but the rates were lower $(68.4 \%, 81.6 \%, 81.6 \%$ and $55.3 \%$, respectively). In our study, no significant difference was detected in INR elevation among groups. This may be because the majority of our patients presented 
Table 4. Comparison of clinical and laboratory findings of the patients by Odds ratio of being CCHF positive versus CCHF negative ones.

\begin{tabular}{|c|c|c|}
\hline Variable & Odds Ratio & \%95 Confidence Interval \\
\hline Fever & 2.64 & $1.21-5.77$ \\
\hline Headache & 2.75 & $1.25-6.02$ \\
\hline Myalgia & 13.32 & $3.01-58.87$ \\
\hline History of tick bite & 2.61 & $1.2-5.71$ \\
\hline Husbandry & 6.8 & $2.91-15.87$ \\
\hline Leucopenia & 10.4 & $4.31-25.16$ \\
\hline Thrombocytopenia & 4.33 & $1.72-10.88$ \\
\hline Lactate dehydrogenase elevation & 3.44 & $1.55-7.63$ \\
\hline Transaminase elevation & 8.41 & $3.31-21.36$ \\
\hline Creatinine $(<1.4)$ & 7.1 & $0.88-56.07$ \\
\hline Myalgia + thrombocytopenia & 5.02 & $2.12-11.91$ \\
\hline Myalgia + transaminase elevation & 9.3 & $3.75-23.05$ \\
\hline Husbandry + thrombocytopenia & 6.25 & $2.59-15.08$ \\
\hline Husbandry + transaminase elevation & 14.12 & $5.18-38.49$ \\
\hline Myalgia + husbandry + thrombocytopenia & 7.8 & $3.05-19.95$ \\
\hline Myalgia + husbandry + transaminase elevation & 15 & $5.27-42.68$ \\
\hline
\end{tabular}

at the pre-hemorrhagic phase. In previous studies, creatinine elevation has not been considered as an important feature in CCHF cases $(2,7,17,18)$. However, in some studies, elevated creatinine level was reported as laboratory findings of CCHF (19). Normal creatinine value was more common among positive cases in our study, but the difference did not reach statistical significance. Even if there is no tick bite history in endemic regions, the diagnosis of CCHF is not ruled out since individuals working in agriculture or husbandry may not recognize tick bite or contact with viremic animals (17, 20, 21). In such cases, the diagnosis should be made based on clinical symptoms and laboratory parameters. Kayadibi et al. developed a diagnostic index based on clinical and laboratory findings (22). In our study, the highest sensitivity (79\%) was detected for the association of myalgia and transaminase elevation while the highest specificity was detected for association of myalgia, history of husbandry and transaminase elevation. In addition, the negative predictive value was found to be higher for these clinical features alone and in combination. CCHF remains to be an important public health issue in Turkey (1). Our data indicated a variable annual number of cases in our region.

This study has some limitations: retrospective design, relatively smaller sample size, and the lack of bilirubin, albumin, fibrinogen, CPK, PT and aPTT values. Nevertheless, it may be pioneering for more comprehensive and larger series.

Our results show that working in agriculture-husbandry, myalgia and transaminase elevation are particularly important in the endemic region. Therefore, it is recommended that specific diagnostic methods such as RT-PCR should be used in cases presenting such features. 
Ethical Approval: Ethics Committee on Non-Interventional Clinical Trials of Karabük University approved the study on December 8, 2019, with decision number 77192459-050.99.E.50692/2019/110.

\section{Informed Consent: N.A.}

Peer-review: Externally peer-reviewed

Author Contributions: Concept - A.A.H.; Design - A.A.H., S.K.; Supervision - A.A.H., S.K.; Fundings - A.A.H., S.K.; Data Collection and/or Processing - A.A.H., S.K.; Analysis and/or Interpretation - ; A.A.H., S.K.; Literature Review - A.A.H., S.K.; Writer -; A.A.H.; Critical Reviews - A.A.H., S.K.

Conflict of Interest: The authors have no conflict of interest to declare.

Financial Disclosure: The authors declared that this study has received no financial support.

\section{REFERENCES}

1 Leblebicioglu H, Ozaras R, Irmak H, Sencan I. Crimean-Congo hemorrhagic fever in Turkey: Current status and future challenges. Antiviral Res. 2016;126:21-34. [CrossRef]

2 Ergonul O. Crimean-Congo haemorrhagic fever. Lancet Infect Dis. 2006;6(4):203-14. [CrossRef]

3 Fillâtre P, Revest M, Tattevin P. Crimean-Congo hemorrhagic fever: An update. Med Mal Infect. 2019;49(8):574-85. [CrossRef]

4 Yilmaz GR, Buzgan T, Irmak H, Safran A, Uzun R, Cevik MA, et al. The epidemiology of Crimean-Congo hemorrhagic fever in Turkey, 2002-2007. Int J Infect Dis. 2009;13(3):380-6. [CrossRef]

5 Yagci-Caglayik D, Korukluoglu G, Uyar Y. Seroprevalence and risk factors of Crimean-Congo hemorrhagic fever in selected seven provinces in Turkey. J Med Virol. 2014;86(2):306-14. [CrossRef]

6 Ertugrul B, Uyar Y, Yavas K, Turan C, Oncu S, Saylak O, et al An outbreak of Crimean-Congo hemorrhagic fever in western Anatolia, Turkey. Int J Infect Dis. 2009;13(6):e431-6. [CrossRef]

7 Ergonul O, Celikbas A, Baykam N, Eren S, Dokuzoguz B. Analysis of risk-factors among patients with Crimean-Congo haemorrhagic fever virus infection: severity criteria revisited. Clin Microbiol Infect. 2006;12(6):551-4. [CrossRef]

8 Kilinc C, Guckan R, Capraz M, Varol K, Zengin E, Mengeloglu Z, et al. Examination of the specific clinical symptoms and laboratory findings of Crimean-Congo hemorrhagic fever. J Vector Borne Dis. 2016;53(2):162-7.

9 Papa A. Diagnostic approaches for Crimean-Congo hemorrhagic fever virus. Expert Rev Mol Diagn. 2019;19(6):531-6. [CrossRef]

10 Sagmak-Tartar A, Balin SO, Akbulut A, Demirdag K. Crimean Congo Hemorrhagic Fever in Eastern Turkey: Epidemiological and Clinical Evaluation. Turkiye Parazitol Derg. 2019;43(1):26-9. Turkish. [CrossRef]

11 Leblebicioglu H, Sunbul M, Guner R, Bodur H, Bulut C, Duygu F, et al. Healthcare-associated Crimean-Congo haemorrhagic fever in Turkey, 2002-2014: a multicentre retrospective cross-sectional study. Clin Microbiol Infect. 2016;22(4):387.e1387.e4. [CrossRef]

12 Pshenichnaya NY, Sydenko IS, Klinovaya EP, Romanova EB, Zhuravlev AS. Possible sexual transmission of Crimean-Congo hemorrhagic fever. Int J Infect Dis. 2016;45:109-11. [CrossRef]
13 Ergonul O, Celikbas A, Yildirim U, Zenciroglu A, Erdogan D, Ziraman I, et al. Pregnancy and Crimean-Congo haemorrhagic fever. Clin Microbiol Infect. 2010;16(6):647-50. [CrossRef]

14 Alavi-Naini R, Moghtaderi A, Koohpayeh HR, Sharifi-Mood B, Naderi M, Metanat M, et al. Crimean-Congo hemorrhagic fever in Southeast of Iran. J Infect. 2006;52(5):378-82. [CrossRef]

15 Sidira P, Maltezou HC, Haidich AB, Papa A. Seroepidemiological study of Crimean-Congo haemorrhagic fever in Greece, 20092010. Clin Microbiol Infect. 2012;18(2):E16-9. [CrossRef.

16 Gozdas HT. Evaluation of Crimean-Congo hemorrhagic fever suspected cases admitted to a secondary care hospital in Kastamonu, Turkey between 2014-2017. Afr Health Sci. 2019;19(1):1433-40. [CrossRef]

17 Karakecili F, Cikman A, Aydin M, Binay UD, Kesik OA, Ozcicek F. Evaluation of epidemiological, clinical, and laboratory characteristics and mortality rate of patients with Crimean-Congo hemorrhagic fever in the northeast region of Turkey. J Vector Borne Dis. 2018;55(3):215-21. [CrossRef]

18 Bakir M, Ugurlu M, Dokuzoguz B, Bodur H, Tasyaran MA, Vahaboglu $\mathrm{H}$, et al. Crimean-Congo haemorrhagic fever outbreak in Middle Anatolia: a multicentre study of clinical features and outcome measures. J Med Microbiol. 2005;54(Pt 4):385-9. [CrossRef]

19 Vashakidze E, Mikadze I. Epidemiology, Clinical and Laboratory Features of Crimean-Congo Hemorrhagic Fever in Georgia. Georgian Med News. 2015(247):54-8.

20 Gunes T, Engin A, Poyraz O, Elaldi N, Kaya S, Dokmetas I, et al. Crimean-Congo hemorrhagic fever virus in high-risk population, Turkey. Emerg Infect Dis. 2009;15(3):461-4. [CrossRef]

21 Mourya DT, Yadav PD, Gurav YK, Pardeshi PG, Shete AM, Jain $\mathrm{R}$, et al. Crimean Congo hemorrhagic fever serosurvey in humans for identifying high-risk populations and high-risk areas in the endemic state of Gujarat, India. BMC Infect Dis. 2019;19(1):104. [CrossRef]

22 Kayadibi H, Yapar D, Akdogan O, Ulusu NN, Baykam N. Hitit Index to distinguish patients with and without Crimean-Congo hemorrhagic fever. Ticks Tick Borne Dis. 2019;10(5):1035-40. [CrossRef] 